\title{
A Local Search for Solving the Multi-item Capacitated Lot Sizing Problem and Vehicle Routing: A Case Study
}

\author{
Ridha Erromdhani, Abdelwaheb Rebaï \\ Laboratory of Modeling and Optimization for Decisional, Industrial and Logistic Systems, Faculty of Economics and Management, \\ University of Sfax, Sfax, Tunisia
}

Email address:

erromdhaniridha@yahoo.fr (R. Erromdhani),abdrebai1953@gmail.com (A. Rebaï)

\section{To cite this article:}

Ridha Erromdhani, Abdelwaheb Rebaï. A Local Search for Solving the Multi-item Capacitated Lot Sizing Problem and Vehicle Routing: A Case Study. International Journal of Management and Fuzzy Systems. Vol. 7, No. 1, 2021, pp. 1-10. doi: 10.11648/j.ijmfs.20210701.11

Received: February 20, 2021; Accepted: March 17, 2021; Published: March 30, 2021

\begin{abstract}
Our research focuses on the development of two algorithms based on the mathematical programming and local search procedures for resolution the Multi-Item Capacitated Lot Sizing Problem and Vehicle Routing Problem (MICLSP-VRP). It concerns so a particularly important and difficult problem in the strong sense for solving. In particular, our study is motivated by a real case study in a butcher's shop firm whose meat processing. Several production lines are considered of (turkey and chicken) items and a fleet of vehicles that is used to deliver. In this study, an effective approach based on the local search and accurate mixed integer programming model is presented to solve multi-item capacitated lot sizing problem and vehicle routing problem with delivery time windows. This consists of determining the production quantities at each site by minimizing the cost of transport and solving the sub problem. By considering an integrated approach, the computational results of a case study show a $25.33 \%$ percent decrease in the total cost production.
\end{abstract}

Keywords: Production Routing Problem, Lot Sizing Problem, Agro Alimentary Industry, Local Search

\section{Introduction}

Production planning is an area rich in complex problems of operations research and combinatorial optimization.

In this study, we introduce the capacitated multi-item lotsizing with vehicle routing problem to make deliveries of products manufactured between sites. In which we begin to present the main features of lot-sizing problems over a planning horizon and their distribution needs.

Our study integrates the problem of production planning in the context of distribution to make deliveries of products manufactured between sites. The problems of lot-sizing are very studied in the literature.

Many works deal these problems for the case of a single type of product, i.e. each product is manufactured at a single production site and each site manufactures a single type of product, to reduce complexity.

Moreover, there are a few articles that deal with batchsizing problems that integrate the distribution. Indeed Chen and Thizy, showed that the multi item capacitated lot-sizing problem is NP-hard in the strong sense [6].

My research focuses on production planning on several sites with transport of products between these sites. The goal is to synchronize the two problems (planning and transport) and apply in real case.

For which, we have developed focuses on mathematical models and algorithms to optimize production planning in the domain of vehicle routing problem with delivery time windows.

We propose two algorithms based on the mathematical programming and local search procedures for resolution the multi-item capacitated lot sizing and vehicle routing problem. The aim of this work is to deal with this coupling between the production problem and the transport problem in a logistics chain. We seek simultaneously to minimize all production costs, preparation and storage and satisfaction of the request and also to minimize transport costs, respecting the constraints of capacity of the vehicles, of transport duration and flow of entry / exit of the products for each site. We present several basic notions for describing the domain that combines lot-sizing problems with the vehicle routing problems based, partially, on: the transport of products $i$ to site $j$, the transformation of raw-materials into a finished or semi-finished product, where we treat it separately on each 
site, the final product demands imposes time and quantity limits for the overall production, the duration of production and delivery, the component stocks on a site, the products that are consumed by the manufacturing of other types of products and also other components, setup times, bill of materials, capabilities are presents in the model for the both problems (production and transport). For the production it associated with each site and it is renewable at each periods. For transportation, it is associated with each vehicle.

Thomas; Pochet and Wolsey integrated a lot-sizing and vehicle routing problem considers machine setup times that result in additional capacity consumption at the beginning of each type of production, such as $[20,17]$. For a more detailed explanation on the use of vehicle routing problem with lotsizing problem in different forms, several researchers are interested:

Glover developed a system that integrates the problem of production and vehicle tours [9].

Chandra and Fisher developed a well-detailed system for analyzing the coordination of distribution and planning production [4].

Lei consider a single product and a set of sites. The method consists in removing the less interesting routes and assigning the best ones to the carriers [12]. This approach tries to optimize the problem of production and transportation simultaneously.

Bard and Nananukul use a similar approach that combines neighborhood-based methods with the advantages of greedy heuristics [2]. To make the delivery, the model has a fleet of vehicles.

Several approaches, resolution methods and models have been studied; Nezhad proposed the lagrangian relaxation approach [16]. It consists of using a production / distribution network with installation costs to study the problem of localization to several products.

To solve this problematic, several researchers have proposed exact methods and other authors are interested in the approaches methods. We can mention the works of Eppen and Martin proposes a transport network based on the shortest path problem for uncapacitated lot-sizing problem [7].

Sambasivan and Yahya, deal with production planning with several sites over several periods in an environment with capacity and transfer between sites [18].

Hwang and Jaruphonga; Lee; and Wolsey proposed a classification by type of lot-sizing problems by adding time windows $[10,22,21]$. Wolsey imposed than production be produced inboard of time windows, where instead of having time limit to make a delivery [21].

There are many impressive researches for solving the problems between production and distribution. Boudia have proposed randomized adaptive search procedure [3]. Is a relatively young metaheuristics that simultaneously tackle production and routing decisions. Lejeune proposed a solution algorithm based on the variable neighborhood decomposition search for solving both production planning and distribution over a multi-period horizon [13]. The proposed methodology based on the exploration of the successive neighborhoods is performed using a branch-andbound algorithm and the variable search neighborhood metaheuristics. Chern and Hsieh have proposed a multiobjective master planning algorithm to solve a master planning problem for a supply chain network with multiple final products [5]. That considers more than one objective and includes seeks to minimize delay penalties, transportation, production, processing, due date constraints and inventory holding costs within capacity. A periodic review inventory-distribution model have been developed in the studies of Kanchanasuntorn and Techanitisawad to solve the case of a fixed-life perishable product and lost sales at retail outlets [11].

Some authors have already given hints about the importance of a production and distribution planning problem. Amorim propose a solution approach for a real world capacitated lot sizing and distribution planning [1]. The problem has been formulated as a vehicle routing problem with time windows and with time-dependent travel times.

Fábio Neves develop an integrated production-routing problem model for solving a multi-product productionrouting problem with delivery time windows [15]. Solyali and Süral tackle the single-vehicle, single-product [19]. The authors present a mathematical formulation and a Lagrangian relaxation based approach for the production-routing problem.

Here we consider a multi-item production system for which several components are considered. The problem also incorporates the delivery of components in addition to the production planning. The developed algorithm is tested in the real case study of a butcher's shop firm whose meat processing. We present a variable neighborhood search metaheuristic for the multi-item capacitated lot sizing problem and vehicle routing problem with delivery time windows.

The main contributions of this paper are: proposing a new mathematical programming formulation with multi-item, multiple vehicles performing routes with delivery time windows, and multi-plant. Specifically, we use the mixed integer programming and efficient metaheuristics based on the variable neighborhood search procedures to obtain high quality initial solutions. We are also interested in we present a decomposition approach for solving the multi-item capacitated lot sizing problem and vehicle routing problem with delivery time windows. For this problem, we consider a production distributed on several sites and the transportation of items between those sites. Furthermore, this analysis and discussion also allows us to point out interesting for integrated problems areas for future research.

The rest of the paper is organized as follows: In Section 2, the multi-item capacitated lot sizing and vehicle routing problem is formulated as a mixed integer linear programming. Details of the proposed hybrid metaheuristic algorithm are presented in Section 3. Section 4 details the case of agro alimentary distribution. Finally, Section 5 summarizes the main concluding remarks and directions for future research. 


\section{A New Mathematical Programming Formulation}

In this section, we present a new mixed integer mathematical formulation of the multi-item capacitated lotsizing problem with setup times and vehicle routing problem with delivery time windows. This problem consists in planning the production of $N$ items over a horizon of $T$ periods in order to be carried at plants $M$. Demands are given for each item $i$ at plant $\mathrm{j}$ during period $t$.

We have a set $V$ of producer sites $\mathrm{j}$ that have to produce products $\mathrm{i}$ to satisfy the demands $D_{i j t}$ in a horizon of T time periods $(\mathrm{t}=1, \ldots, \mathrm{T})$. Where $V_{0}$ is the deposition of vehicles and $V^{\prime}=\left\{V_{1}, \ldots, V_{M}\right\}$ is the set of sites.

We also have a set of $P$ products, and each site $j \in \mathrm{V}^{\prime}$ manufactures products $i$ that belong to a $P_{j} \subset \mathrm{P}$ list of products manufactured on site $j$. Similarly, each product $i$ has a list $V_{i}^{\prime} \subset \mathrm{V}^{\prime}$ of sites that manufacture.

For this operation, we must take into account the production costs $P_{i j t}$, of setup $V_{i j t}$ and storage $H_{i j t}$ at each period $t$. At each site we impose an individual production limit per product $M_{i j t}$ and a renewable production capacity $M_{j t}$ for each period.

This capacity is consumed by the production of product $i$ at the site $j$ at a rate $a_{i j}$, and also by the setup times $b_{i j}$, in the case where several products are manufactured on the site $j$ at the same time. Let $i$ be a product, $j$ and $j^{\prime}$ the manufacturing sites and $t$ the current time period.

The type of the vehicle routing problem is an extension of traveling salesman problem in which we consider a set of cities to be visited in full by a traveler who wants to sell his goods. This problem consists to minimize the total distance traveled by a fleet of homogeneous trucks to ensure delivery. From a mathematical point of view, we can define the vehicle routing problem as a complete directed graph $\mathrm{G}=(\mathrm{V}, \mathrm{E})$, where $\mathrm{V}=\{\mathrm{V} 1, \mathrm{~V} 2, \ldots, \mathrm{Vn}\}$ is the set of $N$ vertices and the set of arcs. Each $\operatorname{arc}(\mathrm{i}, \mathrm{j})$ as an associated $\operatorname{cost} C_{i j}>0$.

The following notations are used in the model formulation. Additional notations will be introduced when needed throughout the paper:

Sets:

$i$ indiquant the product, $i=1, \ldots, N$,

$j$ indiquant the plant, $j=1, \ldots, M$,

$t$ indiquant the period, $t=1, \ldots, T$,

$K$ indiquant set of vehicles

Decision Variables:

$X_{i j t}$ quantity of item $i$ to be produced at plant $j$ during period $t$,

$Y_{i j t}\left\{\begin{array}{l}1, \text { if there is a setup for item } \mathrm{i} \text { at plant } \mathrm{j}, \\ 0, \text { otherwise. }\end{array}\right.$

$S_{i j t}$ quantity to be stored of item $i$ to be produced at plant $j$ during period $t$,
$Z_{i j j^{\prime} t}$ quantity of item $i$ transferred from plant $j$ to plant $j^{\prime}$ in period $t$,

$X_{i j k t}\left\{\begin{array}{l}1, \text { if arc }(\mathrm{i}, \mathrm{j}) \text { is traversed by vehicle } \mathrm{k} \text { in shipping period } \mathrm{t}, \\ 0, \text { otherwise. }\end{array}\right.$

$A_{j k t}\left\{\begin{array}{l}1, \text { if plant } \mathrm{j} \text { is visited by vehicle } \mathrm{k} \text { in shipping period } \mathrm{t}, \\ 0, \text { otherwise. }\end{array}\right.$

$B_{j k t}$ arrival time of vehicle $k$ at location $j$ in period $t$,

$D_{i j k t l}$ quantity of product $i$ to be delivered to location $j$ by vehicle $\mathrm{k}$ in shipping period $t$ to be consumed in period $l$.

Parameters:

$D_{i j t}$ demand for item $i$ at plant $\mathrm{j}$ during period $t$,

$V_{i j t}$ cost of setup for item $i$ at plant $j$ during period $t$,

$P_{i j t}$ unit production cost of item $i$ at plant $j$ in period $t$,

$H_{i j t}$ cost of carrying inventory for item $i$ at plant $\mathrm{j}$ during period $t$,

$J_{i j j^{\prime} t}$ unit minimum transfer cost of item i from plant $j$ to $j^{\prime}$ in period $t$,

$M_{j t}$ available capacity of production at plant $j$ in period $t$,

$a_{i j t}$ time to produce a unit of item $i$ at plant $j$ in period $t$;

$b_{i j t}$ setup time to produce item $i$ at plant $j$ in period $t$;

$\lambda_{i j t}$ unit storage consumption at plant $j$ for period $t$,

$N_{j t}$ storage capacity at plant $\mathrm{j}$ at period $t$,

$M$ a very large number,

$H_{j}$ capacity of the warehouse location $j$,

$f_{i j}$ holding cost of product $i$ location $\mathrm{j}$,

$d_{i j l}$ demand for product i location $j$ in consumption period

$l$,

$V_{k}$ capacity of vehicle $k$,

$t_{i j}$ travel time between $\mathrm{i}$ and $\mathrm{j}$,

$C_{i j}$ travel cost between i and $j$,

[aj, bj] service time window of location $j$ repeated in every period.

Objective Function:

$$
\begin{aligned}
& \operatorname{Min} \sum_{\mathrm{i}=1}^{\mathrm{N}} \sum_{\mathrm{j}=1}^{\mathrm{M}} \sum_{t=1}^{T}\left[V_{i j t} Y_{i j t}+P_{i j t} X_{i j t}+H_{i j t} S_{i j t}\right] \\
& +\sum_{\mathrm{i}=1}^{\mathrm{N}} \sum_{j, j^{\prime} \in M} \sum_{t=1}^{T} J_{i j j^{\prime}} Z_{i j j^{\prime} t}+ \\
& \sum_{(\mathrm{i}, \mathrm{j}) \in \mathrm{V}} \sum_{\mathrm{k} \in \mathrm{K}} \sum_{\mathrm{t}=1}^{\mathrm{T}} \mathrm{C}_{\mathrm{ij}} X_{i j k t}+\sum_{i \in V^{\prime}} \sum_{p \in P} \sum_{k \in K} \sum_{h=0}^{t} \sum_{l=t+1}^{T} f_{i j} D_{i j k h l}
\end{aligned}
$$

Subjet to:

$$
\begin{aligned}
& S_{\mathrm{ij}, \mathrm{t}-1}+X_{i j t}+\sum_{j^{\prime} \in M} Z_{i j^{\prime}, j t}=S_{i j t}+D_{i j t}+\sum_{j^{\prime} \in M} Z_{i j, j^{\prime} t} \\
& \forall \mathrm{i} \in \mathrm{N} ; \forall \mathrm{j} \in \mathrm{M} ; \forall \mathrm{t}=1, \ldots, \mathrm{T}
\end{aligned}
$$




$$
\begin{aligned}
& \sum_{\mathrm{i}=1}^{\mathrm{N}} \lambda_{\mathrm{ijt}} S_{i j t} \leq N_{\mathrm{jt}} \quad \forall \mathrm{j} \in \mathrm{M} ; \forall \mathrm{t}=1, \ldots, \mathrm{T} \\
& \sum_{\mathrm{i}=1}^{\mathrm{N}} \sum_{\mathrm{j}=1}^{\mathrm{M}}\left(\sigma_{\mathrm{ijj} j^{\prime}} \mathrm{Z}_{\mathrm{ijj} j^{\mathrm{t}}}\right) \leq W_{j j^{\prime} t} \forall \mathrm{j}^{\prime} \in \mathrm{M} ; \forall \mathrm{t}=1, \ldots, \mathrm{T} \\
& X_{i j t} \leq M_{\mathrm{ijt}} Y_{i j t} \quad \forall \mathrm{i} \in \mathrm{N} ; \forall \mathrm{j} \in \mathrm{M} ; \forall \mathrm{t}=1, \ldots, \mathrm{T} \\
& \sum_{\mathrm{i}=}^{\mathrm{N}}\left(\mathrm{a}_{\mathrm{ijt}} X_{i j t}+\mathrm{b}_{\mathrm{ijt}} Y_{i j t}\right) \leq M_{\mathrm{jt}} \forall \mathrm{j} \in \mathrm{M} ; \forall \mathrm{t}=1, \ldots, \mathrm{T} \\
& X_{i j t} \leq \sum_{\mathrm{l}=1}^{\mathrm{L}} \sum_{\mathrm{r}=\mathrm{t}}^{\mathrm{T}} \mathrm{D}_{\text {lri }} Y_{i j t} \forall \mathrm{i} \in \mathrm{N} ; \forall \mathrm{j} \in \mathrm{M} ; \forall \mathrm{t}=1, \ldots, \mathrm{T} \\
& X_{i j t} \geq Y_{i j t} \quad \forall \mathrm{i} \in \mathrm{N} ; \forall \mathrm{j} \in \mathrm{M} ; \forall \mathrm{t}=1, \ldots, \mathrm{T} \\
& \sum_{\mathrm{i} \in \mathrm{V}^{\prime}} \sum_{i=1}^{N} \sum_{l=t}^{T} D_{i j k h l} \leq \mathrm{V}_{\mathrm{k}} \quad \forall \mathrm{k} \in \mathrm{K} ; \forall t=1, \ldots, \mathrm{T} \\
& \left\{\begin{array}{l}
\sum_{\mathrm{j} \in \mathrm{V}^{\prime}} \mathrm{X}_{\mathrm{ijkt}}=A_{i k t} \quad \forall \mathrm{i} \in \mathrm{V} ; \forall \mathrm{k} \in \mathrm{K} ; \forall t=1, \ldots, \mathrm{T} \\
\sum_{\mathrm{j} \in \mathrm{V}^{\prime}} \mathrm{X}_{\mathrm{jikt}}=A_{i k t} \quad \forall \mathrm{i} \in \mathrm{V} ; \forall \mathrm{k} \in \mathrm{K} ; \forall t=1, \ldots, \mathrm{T}
\end{array}\right. \\
& B_{\mathrm{jkt}}+\mathrm{t}_{\mathrm{ij}} \leq B_{\mathrm{jkt}}+\mathrm{M}\left(1-\mathrm{X}_{\mathrm{ijkt}}\right) \\
& \forall \mathrm{i} \in \mathrm{V}^{\prime} ; \forall \mathrm{j} \in \mathrm{V}^{\prime} ; \forall \mathrm{k} \in \mathrm{K} ; \forall t=1, \ldots, \mathrm{T} \\
& a_{\mathrm{j}} \leq B_{\mathrm{jkt}} \leq \mathrm{b}_{\mathrm{j}} \forall \mathrm{j} \in \mathrm{V} ; \forall \mathrm{k} \in \mathrm{K} ; \forall t=1, \ldots, \mathrm{T} \\
& X_{\mathrm{ijt}} ; S_{\mathrm{ijt}} ; Z_{\mathrm{ijj} \mathrm{t}_{\mathrm{t}}} ; \mathrm{B}_{\mathrm{jkt}} ; D_{\mathrm{ijkt}} \geq 0 \\
& \forall \mathrm{i} \in \mathrm{N} ; \forall \mathrm{j} \in \mathrm{M} ; \forall \mathrm{t}=1, \ldots, \mathrm{T} \\
& Y_{\mathrm{ijt}} ; X_{\mathrm{ijkt}} ; \mathrm{A}_{\mathrm{jkt}} \in\{0,1\} \\
& \forall \mathrm{i} \in \mathrm{N} ; \forall \mathrm{j} \in \mathrm{M} ; \forall \mathrm{t}=1, \ldots, \mathrm{T}
\end{aligned}
$$

The objective function aims to minimize the production, setup, inventory and transportation costs. Constraints (2) ensure that the demand is satisfied by production at plant $j$ in period $t$ or by inventory from the previous period in the same demanded plant or by production transfers from another plant The production storage capacity constraint at plant $j$ for period $t$ is given by (3). The transfer capacity constraint when transferring items from plant $j$ to plant $j^{\prime}$ at period $\mathrm{t}$ is given by (4). Constraint (5) defines that the production limit for each product.

Constraints (6) restrict the production capacity of each plant $\mathrm{j}$ and each period $\mathrm{t}$; the constraints (7) represent the respect of the upper limit of production for this request. Constraint (8) ensures the obligation to manufacture if there is a setup operation. Constraints (9) are added to the formulation to impose vehicle capacities. Constraints (10) are the so called vehicle flow conservation constraints. In order to define arrival times at each location for each vehicle, constraints (11) are added. The time window of each retail site, which is repeated in every period, is imposed by constraints (12).

(13) and (14) characterize the variable's domain: $X_{i j t}, S_{i j t}$, $Z_{i j j^{\prime} t}, B_{j k t}$ and $D_{i j k t l}$ are non-negative for $i=1, \ldots, N ; j=1, \ldots$, $M$ and $t=1, \ldots, T$ and $Y_{i j t}, X_{i j k t}$ and $A_{i j k t}$ is a binary variable for $i=1, \ldots, N ; j=1, \ldots, M$ and $t=1, \ldots, T$.

Our idea for the proposed approach is to combine the two problems (production and transport) in one common model. This optimization problem is NP-hard, the use of exact methods are usually effective for the problems of small, but for large size problems, these methods require a lot of computing time.

Various decomposition mechanisms are adapted to ensure that multi-item capacitated lot sizing and the vehicle routing aspects of the problem can be solved, regardless of its size.

In this case, the use of the heuristics where the metaheuristics allows to obtained solutions very close to optimality, good quality solutions in the reasonable time. We work essentially on the notions of neighborhood in the local search and disturbances. Thus, the variable neighborhoods search method that exploits the neighborhood structure change.

\section{LSVNS Approach for Solving the MICLSP-VRP-DTW}

In this section, we propose a hybrid algorithm combing variable neighborhood decomposition search with mixed integer programming (MIP), which is based on the basic variable neighborhood search. Thus, the metaheuristics are an efficient tool for solving the multi-item capacitated lot-sizing with vehicle routing problem. Due to the difficulty encountered by exact methods for solving the NP-hard problems.

\subsection{An Effective Local Search Method}

We can strengthen the variable neighborhood structure within a disturbance phase and a local search phase that allows for efficient exploration. The local search that we use is a variable neighborhood search that uses two neighborhood structures; the process consists to move from one solution to another by applying a perturbation.

This combinatorial optimization problem based on the concept of neighborhood among the possible solutions that can be expressed in the form of a research permutations.

Our idea for the proposed approach is consists of breaking down the problem into two sub-problems with a general structure divided into three blocks: a production block, a transport block and a block of delivery time windows. The first consists of the binary variables that will be solved by an approximate method for determining the production days for each product at each site over the time horizon. The second comprises continuous variables that will be solved by an exact method based on mathematical programming to 
determine the production and storage quantities at each site for each item during each period. For the production part on each site, we seek to minimize manufacturing and storage costs in the planning horizon of a site, while respecting the constraints of consumption of production capacity. The goal is to introduce a link between the production of components and their transport between different sites. To find compatible points between the Multi-Item Capacitated Lot Sizing Problem and Vehicle Routing Problem with Delivery Time Windows (MICLSP-VRP-DTW), which have distinct characteristics, we have carried out several tests. For which we have decomposed the problem into several subsets that correspond to intervals of periods and we choose the variables of decision of setup $Y_{i j t}$ and of flow of vehicle $A_{i j t}$

to fix. So, we work with the possible combinations. We get the initial solutions by sequentially solving the production planning, production-delivery and the vehicle routing subproblems. We begin by describing the way how to determine the initial solution of the problem. First, all the elements of the matrix $Y_{i j t}$, are initialized to 1 for all the items $\mathrm{i}$ produced on the site $\mathrm{j}$ and during all the periods $\mathrm{t}$ and the mathematical program will be solved. In order to eliminate these cases, for each $X_{i j t}=0$ we have set $Y_{i j t}=0$ for item $i$ and site $j$ for the period considered. On the basis of this modification within matrix $Y$, the problem will be reformulated and resolved. These steps will be repeated until there is no quantity which corresponds to a preparation $Y_{i j t}$

different from zero.

We propose an approximate procedure based on the local search for the improvement of this solution. Performing movements in the preparation sequence, the neighborhood of such a solution can be defined by the solution obtained by changing one or more components simultaneously.

Local search uses the operator defined by the neighborhood relationship to converge less rapidly to a local optimum. Indeed, this study pushes us to design a local search simple to use and very effective that we based on two structures of neighborhood. This local search is considered fast, it is directly related to the choice of the neighborhood relation used by the value of the objective function which will be calculated after each movement. Subsequently, a new local best optimum will be found and the second neighborhood structure will be realized. Thus, a local search getting a local optimum can continue to iteratively improve a current solution by exploring the movement based on two changes. For this problem, whose solutions can be represented by all possible permutation movements, for each item $i$ manufactures at site $j$ during each period $t$. This operator consists of swapping the values of two distinct periods for a single item $i$ produced at site $j$ in matrix $Y$. The improvement phase is based on a variable neighborhood algorithm in which we use a decomposition scheme that transforms the problem of a multi-product problem into a single-product problem.

\subsection{Variable Neighborhood Search}

In this section, we propose another method, based on the variable neighborhood search algorithm, to solve our problem. This algorithm is a relatively metaheuristic concept developed by Mladenovic, which involves a systematic change in neighborhood structures of the current best solution within randomized local search [14].

The idea was to use the variable neighborhood search and got better results. Using mathematical programming formulations of the problem in different steps of variable neighborhood search has formulation space ingredient.

The main advantage of VNS algorithm, it's capable of finding the optimal solution the routing and lot sizing aspects of the problem, regardless of its size.

The variable neighborhood search algorithm is the most widely used approach to solve various optimization problems We first identify the decomposition procedure and a local search scheme. For this new formulation and for the transport block we are interested in determining the tours of fleet in the vehicles who must deliver whose goal is to minimize the cost associated with these tours. In this case, we seek to build for each site and each period a set of touring to pick up exactly the quantity of items needed. For this, we proposed to solve the capacitated vehicle routing problem with binary variables using a local search algorithm that will allow us to generate solutions following two neighborhood structures. The first is to introduce or eliminate a manufacturing site while the second will allow us to change a manufacturing site by another.

This algorithm builds a set of the rounds touring for satisfying exact the quantity of product $i$ to be delivered to location $j$ by vehicle $\mathrm{k}$ in shipping period $t$ to be consumed in consumption period $l$, this for each service time window of location $\mathrm{j}$ repeated in every period.

We propose two neighborhood structures within one or a more local search method allows setup an effective exploration. These two approaches are broken down into two phases who consisting in constructing a routing scheme in order to minimize the use of the vehicles, that is to say to determine the minimum number of vehicles needed, to identify them touring whose transport cost is also minimal.

This consists of determining the production quantities at each site by minimizing the cost of transport and solving the sub problem. Then, we seek to improve this initial solution by taking into account all the costs defined in the objective function of the problem. The algorithm will stop when the local optimum of the second procedure and the first procedure is the same.

\section{Solving a Real Case in the Agro-alimentary Sector}

This section provides computational experiments which are used to evaluate the performance of our algorithm.

Our algorithm of the mathematical programming and metaheuristics were implemented in $\mathrm{C}++$ and computational tests were runon a Pentium IV $3.2 \mathrm{GHz}$ PC with $1 \mathrm{~GB}$ RAM microprocessor-based personal computer. Here, the 
mathematical model proposed to organize the delivery rounds so as to minimize the total cost function on each product and on each site, while satisfying the demand and constraints of transport and storage capacity. Erromdhani performed tests on a series of instances from a real situation, initially described in [22]. The acquisition of the data is done starting from a textual file which contains following information: the number of vehicles available for this period and their capacities, the number of planning periods, the demand per type per period, the availability of production resources and the unit production period per type.

The decomposition strategy is too common to find approaches that decompose the problems into sets of periods or products and retail sites requires.

The data for these instances is collected from a company in Tunisia. For each of the problem instances, the information on customer demands as well as their locations is obtained from the company. In order to validate our proposed approach, we consider a real case study a meat processing center where several meat products are processed and delivered to several meat stores. The characteristics of the problem include two families: chicken and turkey. Its activities consist in raising, slaughtering and selling of poultries. The planning horizon $(T)$ is set to a week subdivided into 7 periods.

In this paper, we have analyzed one such a real-life multiproduct lot-sizing problem multi-site with a transportation capacity. Consider the case study following with eleven items and four sites. Numerical values are given as follows: (Table 1 and Table 2).

The experimental results of delivery and stock quantities are summarized in Table 3 and Table 4.

Table 1 and table 2 shows partial data for the products with different sites of some finished items for chicken's case. In these problems, the number of items varies between 1 and 40 and the planning horizon is set to a week subdivided into 7 periods.

In this first set of experiments, we test different values of the parameter that determines the values of the production cost and of the production inventory cost. Results are presented in tables 3 and 4. Each lines in these tables provide aggregated results for the four sites. The results suggest that our metaheuristic provides better results are very efficient with regards to the minimization of the number of vehicles.

In order to evaluate the efficiency of our algorithms, we test a large volume database from a real case of the food industry is used for a product-transport combination (multiplant, multi-item, multi -period). Our approach is compared based on the value of the objective function. We calculated the difference between the value of the objective function of the initial solution and that of the solution of our method.

The cost of the solutions of these instances decreases on average by $24.07 \%$ (Table 5) compared to the initial solutions. Indeed, the manufacturer has several items and several alternative production lines, the references are classified by product families and by sites. Table 4 gives a summary of the results obtained on these instances. In this table, we report for each product site the average of the optimal values obtained by compared to our approach.

To evaluate the quality of the solutions obtained by our variable neighborhood search algorithms, we use the total cost of the objective function and the number of vehicles. The approach based on the variable neighborhood search algorithm and mixed integer programming model, which we have developed, shows that for this real case, we get on average very good quality solutions.

Table 1. The prediction of the data for the 11products-4sites of some finished items for chicken's case.

\begin{tabular}{|c|c|c|c|c|c|c|c|c|c|c|c|}
\hline & & & $t=1$ & $\mathbf{t}=\mathbf{2}$ & $\mathbf{t}=\mathbf{3}$ & $t=4$ & $\mathbf{t}=\mathbf{5}$ & $t=6$ & $\mathrm{t}=7$ & $\mathrm{C}_{\mathrm{ij}}$ & $\mathbf{f}_{\mathrm{ij}}$ \\
\hline \multirow{19}{*}{ Site1 } & \multirow{12}{*}{ Demand } & Chicken & 1800 & 1500 & 1000 & 1300 & 1800 & 1100 & 1700 & 18 & 95 \\
\hline & & Turkey & 1000 & 1200 & 2300 & 1800 & 1300 & 2100 & 1600 & 42 & 75 \\
\hline & & Cut out chicken & 1000 & 1200 & 500 & 900 & 1050 & 850 & 1100 & 14 & 80 \\
\hline & & Chicken in the small boot & 450 & 375 & 400 & 275 & 350 & 400 & 420 & 35 & 90 \\
\hline & & Scallop selling & 400 & 350 & 250 & 400 & 550 & 220 & 350 & 17 & 55 \\
\hline & & Scallop congealment & 350 & 360 & 250 & 270 & 200 & 200 & 250 & 22 & 60 \\
\hline & & Wings sale & 150 & 100 & 90 & 130 & 165 & 100 & 110 & 10 & 70 \\
\hline & & Wings congealment & 130 & 100 & 110 & 110 & 100 & 60 & 100 & 24 & 72 \\
\hline & & Thigh sale & 250 & 220 & 200 & 220 & 250 & 140 & 250 & 45 & 68 \\
\hline & & Thigh congealment & 190 & 140 & 200 & 180 & 200 & 115 & 130 & 28 & 87 \\
\hline & & Carcass sale & 85 & 75 & 45 & 60 & 70 & 35 & 50 & 25 & 55 \\
\hline & & Transformation of scallop & 350 & 300 & 250 & 270 & 300 & 210 & 250 & 40 & 92 \\
\hline & \multicolumn{2}{|l|}{$\mathrm{H}_{\mathrm{ijt}}$} & 6 & 6 & 6 & 6 & 6 & 6 & 6 & & \\
\hline & \multicolumn{2}{|l|}{ M } & 80 & 80 & 80 & 80 & 80 & 80 & 80 & & \\
\hline & \multicolumn{2}{|l|}{$\mathrm{V}_{\mathrm{k}}$} & 2500 & 2500 & 2500 & 2500 & 2500 & 2500 & 2500 & & \\
\hline & \multicolumn{2}{|l|}{$\mathrm{P}_{\mathrm{ijt}}$} & 20 & 40 & 50 & 10 & 40 & 25 & 30 & & \\
\hline & \multicolumn{2}{|l|}{$\mathrm{V}_{\mathrm{ijt}}$} & 100 & 100 & 100 & 100 & 100 & 100 & 100 & & \\
\hline & \multicolumn{2}{|c|}{ Number of vehicles } & 11 & 9 & 5 & 4 & 6 & 4 & 4 & & \\
\hline & \multicolumn{2}{|l|}{$\mathrm{M}_{\mathrm{jt}}$} & 2000 & 2000 & 2000 & 2000 & 2000 & 2000 & 2000 & & \\
\hline
\end{tabular}


Table 1. Continue.

\begin{tabular}{|c|c|c|c|c|c|c|c|c|c|c|c|}
\hline & & & $t=1$ & $\mathbf{t}=\mathbf{2}$ & $\mathbf{t}=\mathbf{3}$ & $t=4$ & $t=5$ & $t=6$ & $\mathrm{t}=7$ & $\mathbf{C}_{\mathrm{ij}}$ & $\mathbf{f}_{\mathrm{ij}}$ \\
\hline \multirow{16}{*}{ Site2 } & \multirow{11}{*}{ Demand } & Chicken & 1750 & 1400 & 1000 & 1100 & 950 & 1050 & 1300 & 20 & 85 \\
\hline & & Turkey & 900 & 1500 & 2150 & 1600 & 1200 & 1470 & 1530 & 38 & 78 \\
\hline & & Cut out chicken & 780 & 1310 & 430 & 600 & 1050 & 850 & 1200 & 17 & 75 \\
\hline & & Chicken in the small boot & 550 & 250 & 375 & 280 & 310 & 400 & 420 & 32 & 80 \\
\hline & & Scallop selling & 350 & 390 & 275 & 410 & 275 & 320 & 400 & 21 & 59 \\
\hline & & Scallop congealment & 295 & 375 & 250 & 270 & 195 & 270 & 300 & 26 & 68 \\
\hline & & Wings sale & 145 & 85 & 70 & 120 & 185 & 110 & 110 & 13 & 75 \\
\hline & & Thigh sale & 250 & 230 & 280 & 270 & 310 & 140 & 260 & 42 & 66 \\
\hline & & Thigh congealment & 195 & 170 & 220 & 170 & 210 & 115 & 135 & 31 & 89 \\
\hline & & Carcass sale & 75 & 75 & 55 & 65 & 75 & 25 & 70 & 25 & 40 \\
\hline & & Transformation of scallop & 380 & 310 & 230 & 290 & 310 & 350 & 190 & 37 & 95 \\
\hline & \multicolumn{2}{|l|}{$\mathrm{H}_{\mathrm{ijt}}$} & 6 & 6 & 6 & 6 & 6 & 6 & 6 & & \\
\hline & \multicolumn{2}{|l|}{$\mathrm{M}$} & 80 & 80 & 80 & 80 & 80 & 80 & 80 & & \\
\hline & \multicolumn{2}{|l|}{$\mathrm{V}_{\mathrm{k}}$} & 2500 & 2500 & 2500 & 2500 & 2500 & 2500 & 2500 & & \\
\hline & \multicolumn{2}{|c|}{ Number of vehicles } & 13 & 10 & 7 & 6 & 7 & 5 & 4 & & \\
\hline & \multicolumn{2}{|l|}{$\mathrm{M}_{\mathrm{it}}$} & 2000 & 2000 & 2000 & 2000 & 2000 & 2000 & 2000 & & \\
\hline
\end{tabular}

Table 2. The prediction of the data for the 11products-4sites of some finished items for chicken's case (continued).

\begin{tabular}{|c|c|c|c|c|c|c|c|c|c|c|c|}
\hline & & & $\mathbf{t}=\mathbf{1}$ & $\mathbf{t}=\mathbf{2}$ & $\mathbf{t}=\mathbf{3}$ & $t=4$ & $\mathbf{t}=\mathbf{5}$ & $t=6$ & $t=7$ & $\mathbf{C}_{\mathrm{ij}}$ & $\mathbf{f}_{\mathrm{ij}}$ \\
\hline \multirow{17}{*}{ Site3 } & \multirow{11}{*}{ Demand } & Chicken & 1650 & 1700 & 1100 & 1600 & 1900 & 1150 & 1700 & 22 & 100 \\
\hline & & Turkey & 1100 & 1250 & 2400 & 1900 & 1500 & 2000 & 1400 & 45 & 85 \\
\hline & & Cut out chicken & 1250 & 1350 & 800 & 850 & 1050 & 1000 & 1230 & 17 & 86 \\
\hline & & Chicken in the small boot & 450 & 275 & 380 & 275 & 310 & 400 & 520 & 35 & 91 \\
\hline & & Scallop selling & 440 & 370 & 290 & 380 & 520 & 270 & 360 & 18 & 56 \\
\hline & & Scallop congealment & 355 & 365 & 259 & 278 & 295 & 287 & 265 & 27 & 62 \\
\hline & & Wings sale & 155 & 120 & 105 & 139 & 168 & 99 & 119 & 12 & 72 \\
\hline & & Thigh sale & 265 & 210 & 180 & 225 & 255 & 148 & 265 & 46 & 78 \\
\hline & & Thigh congealment & 192 & 130 & 205 & 185 & 190 & 105 & 135 & 30 & 90 \\
\hline & & Carcass sale & 84 & 95 & 35 & 55 & 70 & 45 & 52 & 32 & 55 \\
\hline & & Transformation of scallop & 355 & 310 & 240 & 265 & 310 & 220 & 230 & 40 & 94 \\
\hline & \multicolumn{2}{|l|}{$\mathrm{H}_{\mathrm{ijt}}$} & 6 & 6 & 6 & 6 & 6 & 6 & 6 & & \\
\hline & \multicolumn{2}{|l|}{ M } & 80 & 80 & 80 & 80 & 80 & 80 & 80 & & \\
\hline & \multicolumn{2}{|l|}{$\mathrm{V}_{\mathrm{k}}$} & 2500 & 2500 & 2500 & 2500 & 2500 & 2500 & 2500 & & \\
\hline & \multicolumn{2}{|c|}{$\mathrm{V}_{\mathrm{ijt}}$} & 100 & 100 & 100 & 100 & 100 & 100 & 100 & & \\
\hline & \multicolumn{2}{|c|}{ Number of vehicles } & 14 & 11 & 7 & 8 & 9 & 7 & 10 & & \\
\hline & \multicolumn{2}{|l|}{$\mathrm{M}_{\mathrm{jt}}$} & 2000 & 2000 & 2000 & 2000 & 2000 & 2000 & 2000 & & \\
\hline
\end{tabular}

Table 2. Continue.

\begin{tabular}{|c|c|c|c|c|c|c|c|c|c|c|c|}
\hline & & & $\mathbf{t}=\mathbf{1}$ & $\mathbf{t}=\mathbf{2}$ & $\mathbf{t}=\mathbf{3}$ & $t=4$ & $\mathbf{t}=\mathbf{5}$ & $t=6$ & $t=7$ & $\mathbf{C}_{\mathrm{ij}}$ & $\mathbf{f}_{\mathrm{ij}}$ \\
\hline \multirow{16}{*}{ Site4 } & \multirow{11}{*}{ Demand } & Chicken & 1950 & 1450 & 1050 & 1100 & 1150 & 1250 & 1600 & 24 & 92 \\
\hline & & Turkey & 1000 & 1500 & 1950 & 1650 & 1400 & 1480 & 1650 & 40 & 68 \\
\hline & & Cut out chicken & 880 & 1410 & 640 & 680 & 1020 & 950 & 1310 & 19 & 75 \\
\hline & & Chicken in the small boot & 450 & 280 & 375 & 292 & 310 & 410 & 510 & 34 & 87 \\
\hline & & Scallop selling & 362 & 374 & 272 & 415 & 280 & 315 & 385 & 23 & 62 \\
\hline & & Scallop congealment & 305 & 415 & 350 & 270 & 295 & 290 & 310 & 27 & 68 \\
\hline & & Wings sale & 147 & 89 & 65 & 128 & 195 & 125 & 110 & 16 & 75 \\
\hline & & Thigh sale & 250 & 235 & 285 & 295 & 400 & 145 & 280 & 52 & 76 \\
\hline & & Thigh congealment & 205 & 185 & 225 & 160 & 230 & 125 & 155 & 33 & 79 \\
\hline & & Carcass sale & 85 & 85 & 65 & 75 & 85 & 35 & 75 & 35 & 47 \\
\hline & & Transformation of scallop & 395 & 310 & 240 & 315 & 285 & 340 & 195 & 39 & 95 \\
\hline & \multicolumn{2}{|l|}{$\mathrm{H}_{\mathrm{ijt}}$} & 6 & 6 & 6 & 6 & 6 & 6 & 6 & & \\
\hline & \multicolumn{2}{|l|}{$\mathrm{M}$} & 80 & 80 & 80 & 80 & 80 & 80 & 80 & & \\
\hline & \multicolumn{2}{|l|}{$\mathrm{V}_{\mathrm{k}}$} & 2500 & 2500 & 2500 & 2500 & 2500 & 2500 & 2500 & & \\
\hline & \multicolumn{2}{|c|}{ Number of vehicles } & 13 & 12 & 6 & 8 & 9 & 6 & 7 & & \\
\hline & \multicolumn{2}{|l|}{$\mathrm{M}_{\mathrm{jt}}$} & 2000 & 2000 & 2000 & 2000 & 2000 & 2000 & 2000 & & \\
\hline
\end{tabular}


Table 3. Delivery and stock quantities in our finished item.

\begin{tabular}{|c|c|c|c|c|c|c|c|c|c|}
\hline \multicolumn{3}{|c|}{ Finished Item } & \multirow{2}{*}{$\begin{array}{l}\mathbf{t}=\mathbf{1} \\
1800\end{array}$} & \multirow{2}{*}{$\begin{array}{l}\mathbf{t}=\mathbf{2} \\
1550\end{array}$} & \multirow{2}{*}{$\begin{array}{l}t=3 \\
965\end{array}$} & \multirow{2}{*}{$\begin{array}{l}\mathbf{t}=\mathbf{4} \\
1300\end{array}$} & \multirow{2}{*}{$\begin{array}{l}\mathbf{t}=\mathbf{5} \\
1800\end{array}$} & \multirow{2}{*}{$\begin{array}{l}\mathbf{t}=\mathbf{6} \\
1088\end{array}$} & \multirow{2}{*}{$\begin{array}{l}t=7 \\
1700\end{array}$} \\
\hline \multirow{12}{*}{ Site1 } & & $\mathrm{X}_{\mathrm{ijt}}$ & & & & & & & \\
\hline & \multirow[t]{3}{*}{ Chicken } & $\mathrm{S}_{\mathrm{ijt}}$ & 0 & 50 & 35 & 12 & 26 & 12 & 21 \\
\hline & & $\mathrm{D}_{\mathrm{ijktl}}$ & 1650 & 1410 & 895 & 1120 & 1710 & 1050 & 1480 \\
\hline & & $X_{\mathrm{ijt}}$ & 1000 & 1200 & 2300 & 1800 & 1300 & 2100 & 1600 \\
\hline & \multirow[t]{2}{*}{ Turkey } & $\mathrm{S}_{\mathrm{ijt}}$ & 0 & 14 & 31 & 14 & 34 & 15 & 45 \\
\hline & & $\mathrm{D}_{\mathrm{ijktl}}$ & 965 & 1100 & 2100 & 1800 & 1205 & 1845 & 1480 \\
\hline & \multirow{3}{*}{$\begin{array}{l}\text { Chicken in } \\
\text { the small } \\
\text { boot }\end{array}$} & $\mathrm{X}_{\mathrm{ijt}}$ & 402 & 350 & 320 & 240 & 316 & 280 & 300 \\
\hline & & $\mathrm{S}_{\mathrm{ijt}}$ & 42 & 68 & 72 & 80 & 63 & 15 & 40 \\
\hline & & $D_{i j k t l}$ & 362 & 340 & 290 & 190 & 310 & 255 & 295 \\
\hline & \multirow{3}{*}{$\begin{array}{l}\text { Scallop } \\
\text { selling }\end{array}$} & $X_{\mathrm{ijt}}$ & 380 & 300 & 240 & 300 & 489 & 189 & 280 \\
\hline & & $\mathrm{S}_{\mathrm{ijt}}$ & 33 & 62 & 71 & 35 & 80 & 32 & 90 \\
\hline & & $\mathrm{D}_{\mathrm{ijktl}}$ & 362 & 269 & 189 & 239 & 447 & 171 & 251 \\
\hline \multirow{2}{*}{\multicolumn{2}{|c|}{ Number of vehicles }} & & 9 & 7 & 3 & 4 & 4 & 4 & 3 \\
\hline & & $\mathrm{X}_{\mathrm{ijt}}$ & 1750 & 1460 & 945 & 1072 & 924 & 1062 & 1325 \\
\hline \multirow{11}{*}{ Site2 } & \multirow[t]{2}{*}{ Chicken } & $\mathrm{S}_{\mathrm{ijt}}$ & 0 & 60 & 55 & 28 & 26 & 0 & 25 \\
\hline & & $\mathrm{D}_{\mathrm{ijktl}}$ & 1600 & 1400 & 900 & 1012 & 866 & 1050 & 1289 \\
\hline & \multirow{3}{*}{ Turkey } & $X_{i j t}$ & 1030 & 1510 & 1980 & 1600 & 1285 & 1483 & 1530 \\
\hline & & $\mathrm{S}_{\mathrm{ijt}}$ & 70 & 10 & 27 & 0 & 85 & 20 & 32 \\
\hline & & $\mathrm{D}_{\mathrm{ijktl}}$ & 930 & 1310 & 1740 & 1500 & 1215 & 1373 & 1410 \\
\hline & \multirow{3}{*}{$\begin{array}{l}\text { Chicken in } \\
\text { the small } \\
\text { boot }\end{array}$} & $X_{\mathrm{ijt}}$ & 570 & 231 & 389 & 285 & 319 & 375 & 420 \\
\hline & & $\mathrm{S}_{\mathrm{ijt}}$ & 20 & 42 & 57 & 15 & 10 & 25 & 0 \\
\hline & & $\mathrm{D}_{\mathrm{ijktl}}$ & 542 & 220 & 375 & 265 & 302 & 355 & 415 \\
\hline & \multirow{3}{*}{$\begin{array}{l}\text { Scallop } \\
\text { selling }\end{array}$} & $\mathrm{X}_{\mathrm{ijt}}$ & 360 & 379 & 282 & 465 & 247 & 355 & 300 \\
\hline & & $\mathrm{S}_{\mathrm{ijt}}$ & 5 & 4 & 15 & 42 & 55 & 40 & 59 \\
\hline & & $\mathrm{D}_{\mathrm{ijktl}}$ & 535 & 200 & 370 & 259 & 300 & 352 & 410 \\
\hline \multicolumn{3}{|c|}{ Number of vehicles } & 8 & 7 & 4 & 4 & 5 & 5 & 4 \\
\hline
\end{tabular}

Table 4. Delivery and stock quantities in our finished item (continued).

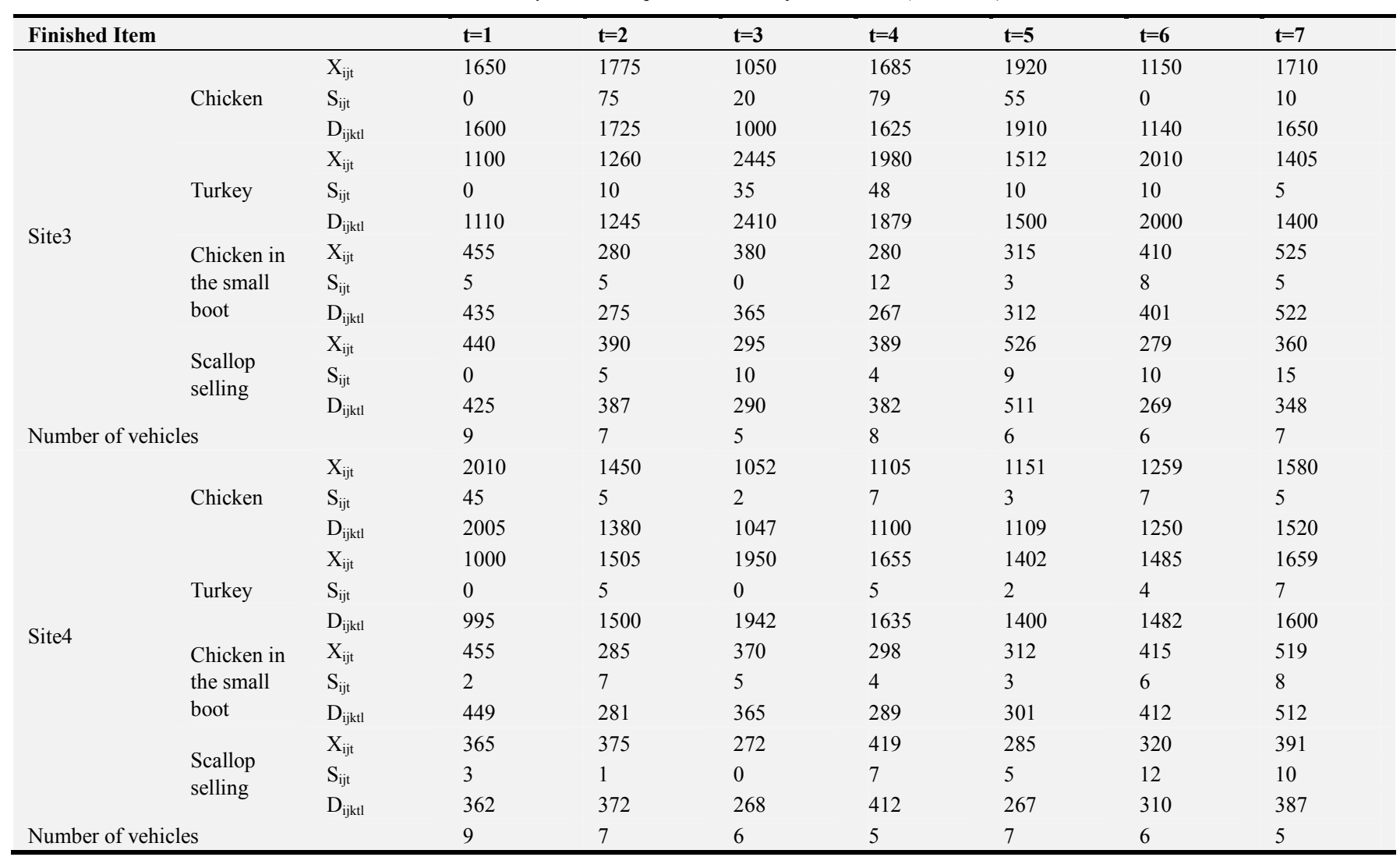


Table 5. Computational experiments of the proposed approach.

\begin{tabular}{|c|c|c|c|c|c|c|c|c|}
\hline \multirow{2}{*}{ Periods } & \multicolumn{4}{|c|}{ Initial solution objective } & \multicolumn{4}{|c|}{ Final solution objective } \\
\hline & Site1 & Site2 & Site3 & Site4 & Site1 & Site2 & Site3 & Site4 \\
\hline $\mathrm{T}=1$ & 92727.87 & 89503.12 & 69217.76 & 82728.25 & 61167.62 & 58329.95 & 53834.98 & 59437.94 \\
\hline $\mathrm{T}=2$ & 60248.84 & 97046.52 & 84746.20 & 82151.64 & 51638.74 & 47715.36 & 48495.46 & 50826.50 \\
\hline $\mathrm{T}=3$ & 100160.73 & 66640.92 & 62165.50 & 86624.74 & 74513.64 & 58962.30 & 57473.90 & 62149.38 \\
\hline $\mathrm{T}=4$ & 17684.72 & 15370.90 & 15342.20 & 15717.54 & 15185.92 & 15189.28 & 15087.90 & 15087.90 \\
\hline $\mathrm{T}=5$ & 52039.36 & 66978.80 & 56825.44 & 58136.60 & 47607.90 & 49285.30 & 44848.46 & 45545.46 \\
\hline $\mathrm{T}=6$ & 75955.70 & 60795.90 & 56907.27 & 56579.60 & 58907.80 & 50208.95 & 50597.95 & 50218.52 \\
\hline Global average & 67116.59 & 67644,92 & 62831,54 & 67959,69 & 52956,32 & 47933,98 & 47704,88 & 49696,09 \\
\hline
\end{tabular}

Table 6. Number of vehicles and percentage of improvement.

\begin{tabular}{|c|c|c|c|c|c|c|c|c|c|c|c|c|}
\hline \multirow{2}{*}{ Periods } & \multicolumn{4}{|c|}{ Number of vehicles } & \multicolumn{4}{|c|}{ Number of vehicles after improvement } & \multicolumn{4}{|c|}{ Improvement (\%) } \\
\hline & Site1 & Site2 & Site3 & Site4 & Site1 & Site2 & Site3 & Site4 & Site1 & Site2 & Site3 & Site4 \\
\hline $\mathrm{T}=1$ & 11 & 13 & 14 & 13 & 9 & 8 & 9 & 8 & 18.18 & 38.46 & 35.71 & 30.77 \\
\hline $\mathrm{T}=2$ & 9 & 10 & 11 & 12 & 7 & 7 & 7 & 7 & 22.22 & 30.00 & 36.36 & 41.66 \\
\hline $\mathrm{T}=3$ & 5 & 7 & 7 & 6 & 3 & 4 & 5 & 6 & 40.00 & 42.85 & 28.57 & 00.00 \\
\hline $\mathrm{T}=4$ & 4 & 6 & 8 & 8 & 4 & 4 & 8 & 5 & 00.00 & 33.33 & 00.00 & 37.50 \\
\hline $\mathrm{T}=5$ & 6 & 7 & 9 & 9 & 4 & 5 & 4 & 6 & 33.33 & 28.57 & 33.33 & 22.22 \\
\hline $\mathrm{T}=6$ & 4 & 5 & 7 & 6 & 4 & 5 & 6 & 6 & 00.00 & 00.00 & 14.28 & 00.00 \\
\hline $\mathrm{T}=7$ & 4 & 4 & 10 & 7 & 2 & 4 & 7 & 4 & 25.00 & 00.00 & 30.00 & 28.57 \\
\hline \multicolumn{9}{|c|}{ Globalaverage } & 19.818 & 24.744 & 25.464 & 22.96 \\
\hline
\end{tabular}

Table 6. Continued.

\begin{tabular}{llll}
\hline Sites & Number of vehicles & Percentage (\%) \\
\hline 1 & 43 & 33 & 23.25 \\
2 & 52 & 37 & 28.84 \\
3 & 66 & 46 & 30.30 \\
4 & 61 & 42 & 31.14 \\
Total & 222 & 158 & \\
\hline
\end{tabular}

Results in table 5 and table 6 show the difference in the improvement between initial solution objective and final solution objective cost after improvement. From the table we can also observe the amelioration on the total number of vehicle used during the seven periods. In fact, the number of vehicles was reduced from 222 in current solution to 158 in the heuristic solution.

\section{Conclusion}

In this paper, we have discussed the importance of integrating the analysis for production and transport for a meat store chain. A novel mathematical formulation was proposed to solve multi-period multi-product multi-site production planning problem and vehicle routing problem with delivery time windows.

Our computational results show the interest of mathematical programming and the effectiveness of the developed local search for the multi-item capacitated lot sizing problem and vehicle routing problem. A real-life case study based on these metaheuristic algorithms would make an interesting research problem. The approach presented might have potential applications to a variety of lot sizing problems and the transportation. This problem deserves a much more in-depth study, which is why we have decided to leave this work in perspective.

\section{References}

[1] Amorim, P., Gunther, H. O. and Almada-Lobo, B. Multiobjective integrated production and distribution planning of perishable products. International Journal Production Economics, (2012).138, 89-101.

[2] Bard, J. F. and Nananukul, N. The integrated productioninventory-distribution- routing problem. Journal of Scheduling, (2009). 3, 257-280.

[3] Boudia, M., Louly, M. A. O. and Prins, C. A reactive GRASP and path relinking for a combined production-distribution problem. Computers \& Operations Research, (2007). 34, 3402-3419.

[4] Chandra, P. and Fisher, M. L. Coordination of production and distribution planning. European Journal of Operational Research, (1994). 72, 503-517.

[5] Chern, C. C. and Hsieh, J. S. A heuristic algorithm for master planning that satisfies multiple objectives. Computers \& Operations Research, (2007). 34, 3491-3513.

[6] Chen, W. H. and Thizy, J. M. Analysis of relaxations for the multi-item capacitated lot-sizing problem. Annals of Operations Research, (1990). 26, 29-72.

[7] Eppen, G. D. and Martin, R. K. Solving Multi-Item Capacitated Lot-Sizing Problems Using Variable Redefinition. Operations Research, (1987). 35, 832-848. 
[8] Erromdhani, R., Eddaly, M., and Rebai, A. Hierarchical production planning with flexibility in agroalimentary environment: a case study. Journal of Intelligent Manufacturing, (2012). 23, 811-819.

[9] Glover, F., Jones, G., Karney, D., Klingman, D. and Mote, J. An integrated production, distribution, and inventory planning system. Interfaces,(1979). 9, 21-35.

[10] Hwang, H. C. and Jaruphongsa, W. Dynamic lot-sizing model with demand time windows and speculative cost structure. Operations Research Letters, (2006). 34, 251-256.

[11] Kanchanasuntorn, K. and Techanitisawad, A. An approximate periodic model for fixed-life perishable products in a twoechelon inventory-distribution system. International Journal of Production Economics, (2006). 100, 101-115.

[12] Lei, L., Liu, S., Park, S. and Ruszczynski, A. On the integrated production, inventory, and distribution routing problem. IIE Transactions, (2006). 38, 955-970.

[13] Lejeune, M. A. A variable neighborhood decomposition search method for supply chain management planning problems. European Journal of Operational Research, (2006). 175, 959976.

[14] Mladenovic, N., Todosijevic, R., and Urosevic, D. AN EFFICIENT GENERALVARIABLE NEIGHBORHOOD SEARCH FOR LARGE TRAVELLING SALESMAN PROBLEM WITH TIME WINDOWS. Yugoslav Journal of Operations Research, (2013).23, 19-30.

[15] Neves-Moreira, F., Almada-Lobo, B., Cordeau, J. F, Guimarães, L. and Jans, R. Solving a large multi- productproduction-routing problem with delivery time windows. Omega, (2018).1-19.

[16] Nezhad, A. M., Manzour, H. and Salhi, S. Lagrangian relaxation heuristics for the uncapacitated single source multiproduct facility location problem. International Journal Production Economics, (2013).145, 713-723.

[17] Pochet, Y. and Wolsey, L. A. Production Planning By Mixed Integer Programming. Springer Series in Operations Research and Financial Engineering. (2006).

[18] Sambasivan, M. and Yahya, S. A Lagrangean-based Heuristic for Multi-plant, Multi-item, Multi-period Capacitated Lotsizing Problems with Inter-plant Transfers. Computers \& Operations Research, (2005). 32, 537-555.

[19] Solyali, Q., Süral, H. A Relaxation Based Solution Approach for the Inventory Control and Vehicle Routing Problem in Vendor Managed Systems. Modeling Computation and Optimization, (2009). 2000, 171-189.

[20] Thomas, L. J., Trigeiro, W. W. and McClain, J. O. Capacitated Lot Sizing with Setup Times. Management Science, (1989). $35,353-366$.

[21] Wolsey, L. A. Lot-sizing with production and delivery time windows. Mathematical Programming, (2006). 107, 471-489.

[22] Yee Lee, C., Çetinkaya, S., and Wagelmans, A. P. M. A Dynamic Lot-Sizing Model with Demand Time Windows. Management Science, (2000).47, 1384-1395. 